\title{
PENGARUH BRAND IMAGE, GAYA HIDUP DAN LOKASI TERHADAP KEPUTUSAN PEMBELIAN CAFÉ TIGA TJERET DI SURAKARTA
}

\author{
Rendika Putri Kartika Sari, Ida Aryati Rochmi Widayanti \\ Fakultas Ekonomi, Universitas Islam Batik Surakarta \\ rendikakartika@gmail.com
}

\begin{abstract}
The purpose of this research aims to find out and explain the simultaneous and partial influence of brand image, lifestyle, and location on the purchasing decisions of the three tjeret café in Surakarta. This research uses descriptive quantitative research design. The population of all visitors to café Tiga Tjeret and having samples using the Sugiyono formula is 100 respondents. The sampling technique uses incidental sampling, a questionnaire used for data collection of multiple linear regression analysis. The results of this study indicate that the test $f$ brand image, lifestyle and location simultaneously and significantly influence the purchasing decision of the café three tjeret in Surakarta. The results of the t test show that the brand image, lifestyle and location have a positive and significant effect on the purchasing decisions of the three tjeret café in Surakarta. The results of the coefficient of determination (R2) show that brand image, lifestyle and location have an effect of 60.9\% on the purchasing decisions of the three teretas café in Surakarta. The dominant influence in café three tjeret purchasing decisions is that lifestyle variables have a t count of 10, 423.
\end{abstract}

Keywords: Brand image, Lifestyle, Location, Purchase decision.

\section{PENDAHULUAN}

Perkembangan sentra bisnis kuliner di Indonesia sangat pesat, pebisnis cenderung diharuskan untuk bekerja cepat dan bergerak sigap untuk meningkatkan kinerja perusahaan, hal ini membuat pengusaha menciptakan peluang usaha dan mempertahankan produk dan jasa agar diterima oleh konsumen, salah satunya dalam peningkatan brand produk serta kualitas agar tidak mengecewakan konsumen dalam memenuhi kebutuhan (Sastika dan Ummah, 2016). Majunya perekonomian ditandai dengan pertumbuhan industri ketat, bisnis terus meningkat serta mengalami kemajuan, dimana perusahaan menciptakan produk baru untuk melakukan strategi pemasaran serta inovasi produk untuk memperkenalkan dan menjual produk pada daerah yang belum terjangkau (Ulus, 2013). Pemasaran efektif serta hasil perencanaan yang tepat membuat barang dan jasa bisa cepat dikenal masyarakat. Kota Surakarta merupakan sentra bisnis dengan laju peningkatan beraneka ragam, banyaknya pesaing membuat perusahaan menciptakan ide baru dalam pengelolaan bisnis agar kebutuhan konsumen terpenuhi. Pesaing bisnis mulai tersebar luas semakin banyak jumlah pesaing, membuat perusahaan menciptakan inovasi agar bisa mempertahankan brand perusahaan meski banyak bisnis sama (Tarigan, 2017).

Persaingan ketat membuat perusahaan berusaha untuk bertahan agar bisa bersaing. Banyak perusahaan melakukan pemasaran internasional akan berdampak pada produk yang 
dibuat suatu negara. Perusahaan harus bisa menjalankan strategi pemasaran handal agar menarik minat konsumen sehingga berhasil memenangkan pasar dan mendapatkan laba (Hasiolan dkk, 2017). Kemajuan teknologi pesat serta perubahan lingkungan, pebisnis melakukan perubahan inovasi untuk memenuhi kebutuhan konsumen yang beraneka ragam serta mempertahankan konsumen menghadapi persaingan bisnis, macam usaha dilakukan untuk menciptakan produk unggul serta kegiatan pemasaran menimbulkan perusahaan melakukan strategi mempengaruhi pasar dan mencapai target penjualan (Ardy, 2013).

Pratama,dkk (2017) berpendapat, bahwa keputusan pembelian memiliki faktor penting bagi konsumen untuk menentukan eksitensi perusahaan, agar menjadi tolak ukur suatu rangsangan konsumen dalam memutuskan pembelian produk pasar dan mendapatkan respon positif. Keputusan pembelian merupakan keputusan untuk membeli berasal dari seseorang dipengaruhi lingkungan, kebudayaan, dan keluarga akan membentuk sikap pada diri individu untuk melakukan pembelian (Sunarso dkk., 2016).

Karakteristik individu atau kelompok dalam hal menilai barang yang dibeli memiliki faktor perilaku konsumen meliputi faktor tingkat pendidikan, usia, tingkat penghasilan dan rasa membeli dapat mempengaruhi brand image serta gaya hidup (Amron, 2018). Faktor mendasar yang menjadi keputusan pembelian yaitu brand image, hal terkait merek berada dibenak konsumen atau kesan tentang image, konsumen harus memiliki citra positif terhadap image untuk melakukan pembelian, penciptaan kesan menjadi dasar orientasi pemasaran moderen, yaitu lewat pemberian perhatian serta penciptaan merek (Fatmawati\&Soliha, 2017).

Perusahaan harus meningkatkan kualitas produk yang mereka miliki demi mempertahankan brand image. Produk unggul akan menjadi persepsi tersediri bagi masyarakat terhadap produk kemajuan perusahaan. Brand bisa menjadi sinyal konsumen untuk melindungi dari pesaing serta berusaha menyediakan produk identik terbentuk maupun melekat dibenak konsumen (Sunarso dkk., 2016). Brand image termasuk faktor yang mempengaruhi pengambilan keputusan pembelian konsumen dan brand image yang baik akan berdampak positif bagi perusahaan serta dapat memberikan keuntungan perusahaan melalui peningkatan pembelian konsumen terhadap produk tersebut (Tarigan \& Adiwidjaja, 2017)

Soepeno, dkk (2015) berpendapat, bahwa gaya hidup menunjukan seseorang individu bagaimana orang tersebut hidup, serta membelanjakan uangnya dan mengatur waktu mereka dengan sebaik-baiknya. Suryoko dan Suharto, (2017) berpendapat bahwa, gaya hidup moderen akan menjadi persepsi konsumen karena harga bukan faktor pertimbangan utama berkunjung ke café, namun suasana menjadi daya tarik tersendiri bagi konsumen.

Nurseto, dkk (2016) bahwa lokasi, memiliki peran penting bagi perusahaan untuk menarik perhatian konsumen dan lokasi strategis mempengaruhi kepuasan konsumen dalam melakukan pembelian, banyak perusahaan menciptakan usaha dekat rumah, aktivitas, mudah dijangkau transportasi umum serta memudahkan konsumen datang ke tujuan. Pengeluaran sedikit serta pengorbanan dari sisi tenaga, materi dan tingkat kepuasaan konsumen merupakan titik ukur kesuksesaan usaha, semakin besar rasa kepuasaan akan membuat usaha semakin maju (Sinambow, 2015). Pemilihan lokasi strategis ikut menentukan tercapainya tujuan kemajuan dalam bisnis, tempat menarik, akses mudah dan area parkir luas akan menjadi dasar pemilihan tersendiri bagi konsumen untuk pemutusan pembelian, pada dasarnya tingkat harga, fasilitas 
berkaitan dengan kelancaran perusahaan serta memilih tempat rekomen Café Tiga Tjeret sebagai pemilihan Café favorit (Adiwinata\&Atmaja, 2013).

Kota Surakarta merupakan pusat kuliner bisnis makanan malam yang sudah terkenal pada era sebelumnya berada di jawa tengah. Penjual menciptakan brand baru agar menarik masyarakat sendiri maupun domestik. Salah satunya Café Tiga Tjeret merupakan café berbentuk wedangan dan memiliki brand sudah terkenal dikalangan masyarakat umum. Menjual berbagai hidangan jawa memiliki segmen pasar menengah atas, serta target kalangan menengah bawah. Gaya hidup setiap individu tidak membuat kosumen berhenti dan mencoba menikmati café bergaya kelas mewah.

Café beroperasi bulan desember tahun 2012 desain diciptakan semenarik mungkin, suasana café nyaman membuat konsumen tidak merasa bosan serta lokasi dan akses mudah berada ditengah kota beralamat di jalan Ronggowarsito No 97, Keprabon, Kecamatan Banjarsari, Surakarta, Jawa Tengah. Mencicipi makanan, minuman dan bersantai bersama keluarga, sahabat untuk menikmati kuliner tradisional yang disediakan serta hiburan music. Café ini memberikan konsep sel-service atau prasmanan tetap dipertahankan pada Café Tiga Tjeret. Menu makanan dan minuman yang disediakan menambah selera serta menikmati hidangan suasana malam. Pelayanan ramah, sopan, dan fasilitas memadai membuat café menjadi tempat favorit untuk acara formal maupun non formal.

Dari uraian latar belakang diatas maka peneliti dapat merumuskan permasalahan sebagai berikut:

1) Apakah memiliki pengaruh secara simultan brand image, gaya hidup, dan lokasi terhadap keputusan pembelian Café Tiga Tjeret di Surakarta?

2) Apakah memiliki pengaruh brand image terhadap keputusan pembelian Café Tiga Tjeret di Surakarta?

3) Apakah memiliki pengaruh gaya hidupterhadap keputusan pembelian Café Tiga Tjeret di Surakarta?

4) Apakah memiliki pengaruh lokasi terhadap keputusan pembelian Café Tiga Tjeret di Surakarta?

Tujuan dari penelitian ini untuk mengetahuai secara simultan dan parsial variabel brand image, gaya hidup, dan lokasi terhadap keputusan pembelian Café Tiga Tjeret di Surakarta.

\section{TINJAUAN PUSTAKA}

\subsection{Keputusan Pembelian}

Memahami perilaku konsumen merupakan suatu hal penting dalam bisnis karena setiap konsumen memiliki alasan yang untuk memilih produk, serta konsumen bisa membeli produk atas dasar kualitas dan layanan dari produk yang didapat (Wijaya, 2015). Perilaku konsumen merupakan suatu dinamika rangkaian antara interaksi pengaruh kesadaraan, baik perilaku serta lingkungan dan manusia dapat melaksanakan aspek-aspek kehidupan. Soepeno, dkk (2016) berpendapat bahwa, keputusan pembelian merupakan hal dalam pemilihan dua atau lebih alternative pada pemutusan pembelian barang, yang berarti seseorang dapat menyusun alternatif dari pilihan tersebut. 


\subsection{Brand Image}

Brand image merupakan seluruh persepsi terhadap image tertentu dan dibuat melalui informasi pengalaman masa lalu terhadap image (Hasiolan dkk., 2017). Diallo, dkk (2013) menempatkan brand image sebagai pencitraan produk tertentu di benak konsumen secara masal dan setiap orang akan mempuyai pencitraan sama terhadap brand tertentu didunia industri.

\subsection{Gaya Hidup}

Merupakan cara seseorang untuk menunjukan bagaimana orang hidup, mereka membelanjakan uangnya, dan mereka mengalokasikan waktunya (Soepeno dkk., 2015). Tarigan, (2016) berpendapat bahwa, gaya hidup mendorong individu untuk melakukan pemenuhan kebutuhan serta sikap individu dalam mempengaruhi aktivitas dan penggunaan produk, untuk pendorong dalam proses pengambilan keputusan seseorang dalam membeli produk tersebut.

\subsection{Lokasi}

Nurseto dkk, (2016) bahwa, lokasi merupakan dasar bagi konsumen yaitu lokasi merupakan keputusan yang dibuat perusahaan berkaitan dengan operasi pegawai yang akan ditempatkan, lokasi penting bagi perusahaan karena mempengaruhi kedudukan suatu perusahaan dalam persaingan IndustrI. Pemilihan lokasi mempuyai fungsi strategis karena dapat ikut menentukan tercapainya tujuan dan usaha bagi konsumen.Pemilihan lokasi strategis ikut menetukan tercapainya tujuan kemajuan dalam bisnis (Adiwinata dan Atmaja, 2013).

\section{METODE PENELITIAN}

Penelitian kuantitatif tempat penelitian Café Tiga Tjeret Surakarta.waktu penelitian dilakukan kurang lebih 3 bulan dari bulan November 2018 sampai dengan bulan Januari 2019. Populasi penelitian konsumen Café Tiga Tjeret berjumlah tidak terhingga. Sampel penelitian jumlah populasinya tidak diketahui secara pasti untuk menentukan sampelnya menggunakan rumus Sugiyono (2009: 85) maka sampelnya dibulatkan menjadi 100 responden untuk mengetahui populasi yang tidak terhingga. Teknik pengambilan sampel dalam penelitian ini

Teknik sampling, penulis memilih menggunakan teknik non-probability sampling dimana teknik ini tidak memberi peluang/kesempatan sama bagi setiap unsuratau anggota populasi untuk dipilih menjadi sampel (Sugiyono, 2012: 120). Pengambilan sampel yaitu accidental sampling, pengambilan sampel berdasarkan kebetulan saja secara kebetulan bertemu dengan peneliti dapat digunakan sebagai sebagai sampel jika orang yang kebetulan dijumpai dianggap cocok sebagai sumber data (Sugiyono,2009: 122).

\section{HASIL DAN PEMBAHASAN PENELITIAN}

\subsection{Analisis Data}

\subsubsection{Uji Asumsi Klasik}

a. Uji Normalitas

Untuk pengujian normalitas dalam penelitian ini menggunakan kolmogrovsmirnov test 0,05 dan asymp.sig 0,894 dengan nilai signifikan model regresi lebih 
besar dari 0,05 maka dapat disimpulkan penelitian ini mempuyai sebaran data normal.

b. Uji Multikolinearitas

Uji Multikolinearitas uji ini bertujuan untuk menguji apakah terdapat model regresi ditemukan adanya suatu korelasi antar variabel bebas. Untuk menguji ada atau tidaknya multikolinearitas dengan cara yaitu menggunakan nilai Variance Inflation Factor (VIF). Dari hasil uji multikolinearitas dapat dilihat pada tabel berikut ini :

Tabel 1. Uji Multikolinearitas

\begin{tabular}{lccl}
\hline Keterangan & Tolerance & VIF & \multicolumn{1}{c}{ Keterangan } \\
\hline $\begin{array}{l}\text { Variabel } \\
\text { brand image }\end{array}$ & 0,934 & 1,070 & $\begin{array}{l}\text { Tidak terjadi } \\
\text { multikolinearitas }\end{array}$ \\
$\begin{array}{l}\text { Variabel } \\
\text { gaya hidup }\end{array}$ & 0,916 & 1,092 & $\begin{array}{l}\text { Tidak terjadi } \\
\text { multikolinearitas }\end{array}$ \\
$\begin{array}{l}\text { Variabel } \\
\text { lokasi }\end{array}$ & 0,927 & 1,079 & $\begin{array}{l}\text { Tidak terjadi } \\
\text { multikolinearitas }\end{array}$ \\
\hline
\end{tabular}

Dari tabel diatas dapat dijelaskan bahwa variabel brand image, variabel gaya hidup, dan variabel lokasi memiliki nilai tolerance $>0,10$ dan nilai $\mathrm{VIF}<0,10$. Jadi ketiga variabel tersebut tidak terjadi multikolinearitas.

c. Uji hetroskedastisitas dapat dilakukan dengan menggunakan uji glejser, maka dapat dilihat hasilnya pada tabel dibawah ini :

Tabel 2. Uji Hetroskedastisitas

\begin{tabular}{lcc}
\hline \multicolumn{1}{c}{ Keterangan } & $\begin{array}{c}\text { Nilai signifikan } \\
\text { (P value) }\end{array}$ & Kesimpulan \\
\hline Variabel brand image & 0.044 & Tidak terjadi heteroskeditas \\
Variabel gaya hidup & 0.000 & Tidak terjadi heteroskeditas \\
Variabel lokasi & 0.009 & Tidak terjadi heteroskeditas \\
\hline
\end{tabular}

Dari tabel diatas dapat dijelaskan bahwa variabel brand image, variael gaya hidup dan variabel lokasi memiliki nilai signifikan $>0,05$. Jadi ketiga variabel tersebut tidak terjadi heteroskedastisitas.

\subsection{Pengujian Hipotesis}

4.2.1 Analisis Regresi Linier Berganda

Digunakan untuk mengetahui seberapa besar pengaruh brand image $\left(\mathrm{X}_{1}\right)$, gaya hidup $\left(\mathrm{X}_{2}\right)$, dan lokasi $\left(\mathrm{X}_{3}\right)$ terhadap keputusan pembelian. Berikut ini hasil analisis regresi linier berganda dijelaskan pada tabel berikut ini : 
Tabel 3 : Analisis Regresi Linier Berganda

\begin{tabular}{ccrrrc}
\hline \multicolumn{1}{c}{ Variabel } & \multicolumn{1}{c}{ B } & \multicolumn{1}{c}{ Beta } & \multicolumn{1}{c}{$\mathrm{t}_{\text {hitung }}$} & Sig t & Ket \\
(Constant) & .147 & & & & \\
Brand image & .135 & .133 & 2,042 & 0,044 & Signifikan \\
Gaya hidup & .687 & .685 & 10,423 & 0,000 & Signifikan \\
Lokasi & .184 & .175 & 2,676 & 0,009 & Signifikan \\
F hitung & 52,301 & & & & \\
Sig F & 0,000 & & & & \\
R square & 0,609 & & & & \\
\hline Variabel & Keputusan & Pembelian & & & \\
dependent & & & & & \\
\hline
\end{tabular}

Dari persamaan regresi berganda diatas hasil analisis yang terdapat dalam perhitungan yaitu:

$$
Y=0,147+0,135 X_{B}+0,687 X_{G}+0,184 X_{L}+e
$$

Keterangan :

a. Nilai konstanta (Y) Sebesar 0,147 artinya apabila variabel independen yaitu brand image, gaya hidup, dan lokasi nilainya adalah 0 (nol), maka variabel keputusan pembelian (Y) akan berada pada angka 0,147.

b. Koefisien variabel brand image $\left(\mathrm{b}_{1}\right)$ dari perhitungan regresi linier berganda nilai coefficients $(b)=0,135$. Hal ini menunjukan bahwa variabel brand image berpengaruh positif terhadap keputusan pembelian, artinya jika brand image meningkat, sementara variabel gaya hidup dan lokasi (nol), maka keputusan pembelian akan meningkat sebesar 0,135.

c. Koefisien variabel gaya hidup $\left(b_{2}\right)$ dari perhitungan regresi linier berganda nilai coefficients $(b)=0,687$. Hal ini menunjukan bahwa variabel gaya hidup berpengaruh positif terhadap keputusan pembelian, artinya jika gaya hidup meningkat, sementara variabel brand image dan lokasi tetap (nol), maka keputusan pembelian akan meningkat sebesar 0,687.

d. Koefisien variabel lokasi $\left(b_{3}\right)$ dari perhitungan regresi linier berganda nilai coefficients (b) $=0,184$. Hal ini menunjukkan bahwa variabel lokasi berpengaruh positif terhadap keputusan pembelian, artinya jika lokasi meningkat, sementara variabel brand image dan gaya hidup tetap (nol), maka keputusan pembelian akan meningkat sebesar 0,184.

\subsubsection{Koefisien determinasi R2}

Hasil perhitungan data dari analisis regresi linier berganda dapat diketahui besarnya koefisien determinasi (Adjusted R2) didapat dari 0,609 atau 60,9\%.

Ini menunjukan bahwa 60,9\% keputusan pembelian Café Tiga Tjeret dipengaruhi oleh variabel independen berupa variabel brand image, gaya hidup dan lokasi. Sedangkan $39,1 \%$ dipengaruhi oleh variabel lain diluar variabel penelitian. 


\subsubsection{Uji F simultan}

Digunakan untuk melihat atau mengetahui signifikansi pengaruh brand image, gaya hidup, dan lokasi secara simultan terhadap keputusan pembelian. Hasil uji F bisa dilihat dari hasil output analisis data pengujian uji $\mathrm{F}$ terdapat pada tabel 1 diperoleh nilai $\mathrm{F}$ hitung lebih besar dari $\mathrm{F}$ tabel yaitu 52,301 > 2,70 dengan signifikan 0,000<0,005. maka dari hasil tersebut Ho ditolak artinya brand image, gaya hidup, dan lokasi secara simultan dan signifikan berpengaruh terhadap keputusan pembelian Café Tiga Tjeret di Surakarta.

\subsubsection{Uji t parsial}

Digunakan untuk menguji signifikan secara parsial pengaruh variabel independen terdiri dari brand image, gaya hidup dan lokasi terhadap variabel dependen yaitu keputusan pembelian. Berdasarkan hasil analisis penelitian pada tabel $\mathrm{t}$ dapat ditarik kesimpulan yaitu

1) Variabel brand image hasil nilai $t_{\text {hitung }}(2,042)>t_{\text {tabel }}(1,985)$ signifikan $0,044<0,05$ dapat diambil kesimpulan secara parsial bahwa brand image memiliki pengaruh positif dan signifikan terhadap keputusan pembelia Café Tiga Tjeret di Surakarta.

2) Variabel gaya hidup hasil nilai $t_{\text {hitung }}(10,423)>t_{\text {tabel }}(1,985)$ signifikan $0,000<0,05$ dapat diambil kesimpulan secara parsial gaya hidup memiliki pengaruh positif dan signifikan terhadap keputusan pembelian Café Tiga Tjeret di Surakarta.

3) Variabel lokasi hasil nilai $t_{\text {hitung }}(2,676)>t_{\text {tabel }}$ signifikan $0,009<0,05$ dapat diambil kesimpulan secara parsial lokasi memiliki pengaruh positif dan signifikan terhadap keputusan pembelian Café Tiga Tjeret di Surakarta.

\subsection{Pembahasaan}

Hasil penelitian secara parsial menunjukan bahwa brand image berpengaruh positif dan signifikan terhadap keputusan pembelian Café Tiga Tjeret di Surakarta. Hal ini juga didukung jawaan dengan kuesioner responden yang pernah berkunjung ke Café Tiga Tjeret. Brand image merupakan segala hal terkait merek yang ada dibenak konsumen atau kesan tentang image Café Tiga Tjeret serta konsumen harus memiliki citra positif terhadap image untuk melakukan pembelian, penciptaan kesan menjadi dasar orientasi pemasaran moderen.

Hasil penelitian secara parsial menunjukan bahwa gaya hidup berpengaruh positif dan signifikan terhadap keputusan pembelian Café Tiga Tjeret di Surakarta. apabila pola gaya hidup tinggi, maka keputusan pembelian Café Tiga Tjeret di Surakarta meningkat. Menunjukan bahwa semakin baik persepsi konsumen terhadap variabel gaya hidup.

Hasil penelitian secara parsial menunjukan bahwa lokasi berpengaruh positif dan signifikan terhadap keputusan pembelian Café Tiga Tjeret di Surakarta, lokasi yang strategis akan mempengaruhi kepuasaan konsumen dalam melakukan pembelian. 


\section{KESIMPULAN DAN SARAN}

\subsection{Kesimpulan}

Dari hasil penjelasan diatas maka penulis menyimpulkan bahwa sebgai berikut :

1) Secara parsial variabel brand image, gaya hidup dan lokasi memilki pengaruh positif dan signifikan terhadap keputusan pembelian Café Tiga Tjeret di Surakarta.

2) Nilai $R^{2}$ sebesar 0,609 atau 60,9\% artinya bahwa variabel brand image, gaya hidup dan lokasi mempuyai pengaruh sebesar $60,9 \%$ terhadap keputusan pembelian sisanya sebesar $39,1 \%$ dipengaruhi oleh variabel diluar penelitian seperti harga, promosi dan kualitas pelayanan.

\subsection{Saran}

1) Diharapkan agar Café Tiga Tjeret menciptakan desain Café yang unik dan instragramnable sehingga memunculkan brand tersendiri bagi konsumen.

2) Sebaiknya untuk menarik konsumendari luar surakarta, lokasi Café berada diwilayah yang bisa diaksessemua orang.

3) Bagi peneliti selanjutnya disarankan untuk melakukan penelitian dengan objek penelitian berbeda, karena masih terdapat pengaruh variabel lain diluar penelitian seperti kualitas pelayanan, harga dan promosi.

\section{DAFTAR PUSTAKA}

Adiwinata Febrian Martinus \& Atmaja Purwanti Desi. 2013. Pengaruh Produk, Harga, Lokasi, Dan Kualitas Layanan Terhadap Keputusan Pembelian Di Kopitiam Oey Surabaya. Jurnal Hospitally dan Manajemen Jasa (JHMJ).Vol.1 NO.2

Ardy Puspita Ayu Dian, Pengaruh Gaya Hidup, Fitur Dan Harga Terhadap Keputusan Pembelian Blackberry Curve 9300. Jurnal IlmuManajemen. Vol. 1, No. 1.Januari 2013.

Fatmawati Nurul dan Soliha Euis.Kualitas produk, Citra Merek Dan Persepsi Harga Terhadap Proses Keputusan Pembelian Konsumen Sepeda Montor Matic "Honda".Jurnal Manajemen Teori Dan Terapan. Vol. 10 No. 1 April 2017.

Hasiholan Budi, Leonardo, Fathoni Azis dan Pratama, S.B. 2017. Analisis Pengaruh Brand Image, Kualitas Produk dan Harga Terhadap Keputusan Pembelian Produk Kartu PerdanaTelkomsel. Journal Of Management Vol. 3 No. 3

Nurseto Sendhang, Hidayat.W dan Pangeggar. G, 2016. Pengaruh Kualitas Pelayanan, Lokasi, dan Fasilitas Terhadap Keputusan Pembelian Warung Kopi Tunjang Café. Jurnal Ilmu Administrasi Bisnis (JIAB). Vol. 5 No. 1

Sastika, Widya dan Ummah.M. Pengaruh Brand Image Terhadap Keputusan Pembelian Café Lawang Wangi Creative Space (Studi pada Masyarakat Bandung). E-proceeding Of Applied Science. Volume 2, No. 2.Agustus 2016.ISSN 2442-5826. 
Soepeno, et al. 2015. Analisis Kualitas Produk, Brand Image, dan Lifestyle Terhadap Keputusan Pembelian Pakaian Wanita di Mississippi Manado Town Squere. Jurnal EMBA. Vol. 3 No. 1. Hal 1096-1105.

Sinambow.S dan Trang. I. 2015. Pengaruh Harga, Lokasi, Promosi dan Kualitas LayananTerhadap Keputusan Pembelian Pada Toko Komputer Game Mall Manado. Jurnal EMBA. 3 (3), 300-311. ISSN 2303-11Zone Mega

Sugiyono. 2009. Metode Penelitian Bisnis.Bandung: Alfabeta. . 2012. Metode Penelitian Pendidikan Pendekatan Kuantitatif, Kualitatif dan R\&D. Bandung: Alfabeta.

Sunarso, Putri, M.W.P.danWardiningsih, S.S. 2016. AnalisisPengaruh Citra Merek, KesadaranMerek, Persepsi Kualitas dan Loyalitas Merek Terhadap Keputusan Pembelian Sepatu Adidas, Jurnal Ekonomi dan Kewirausahaan. Volume 16, Nomor 2 Hal 234-241.

TariganJiwa. Z. danAdiwidjaja. J. 2017. Pengaruh Brand Image dan Brand Trust Terhadap Keputusan Pembelian Sepatu Converse.AGORA.Vol. 5 No. 2

Ulus Agnes. A. Bauran Pemasaran pengaruhnyaTerhadap Keputusan Pembelian Mobil Daihatsu di PT. Astra Internasional Manado.Jurnal Riset Ekonomi, Manajemen, Bisnis dan Akutansi (EMBA). Vol. 1 No. 4 Desember. 2013, 1134-114. ISSN: 2303-1174 